\title{
A Model-Based Methodology for Spray-Drying Process Development
}

\author{
Dan E. Dobry • Dana M. Settell • John M. Baumann • \\ Rod J. Ray • Lisa J. Graham • Ron A. Beyerinck
}

Published online: 25 July 2009

(C) The Author(s) 2009. This article is published with open access at Springerlink.com

\begin{abstract}
Solid amorphous dispersions are frequently used to improve the solubility and, thus, the bioavailability of poorly soluble active pharmaceutical ingredients (APIs). Spray-drying, a well-characterized pharmaceutical unit operation, is ideally suited to producing solid amorphous dispersions due to its rapid drying kinetics. This paper describes a novel flowchart methodology based on fundamental engineering models and state-of-the-art process characterization techniques that ensure that spray-drying process development and scale-up are efficient and require minimal time and API. This methodology offers substantive advantages over traditional process-development methods, which are often empirical and require large quantities of API and long development times. This approach is also in alignment with the current guidance on Pharmaceutical Development Q8(R1). The methodology is used from early formulation-screening activities (involving milligrams of API) through process development and scale-up for early clinical supplies (involving kilograms of API) to commercial manufacturing (involving metric tons of API). It has been used to progress numerous spray-dried dispersion formulations, increasing bioavailability of formulations at preclinical through commercial scales.
\end{abstract}

\section{Introduction}

Spray-drying is a widely used unit operation for pharmaceutical applications. In addition to its use in preparing solid amorphous

D. E. Dobry $(\bowtie) \cdot$ D. M. Settell $\cdot$ J. M. Baumann $\cdot$ R. J. Ray $\cdot$

L. J. Graham $\cdot$ R. A. Beyerinck

Bend Research Inc.,

64550 Research Road,

Bend, OR 97701, USA

e-mail: dobry@bendres.com spray-dried dispersions (SDDs), spray-drying is used in excipient manufacture, pulmonary and biotherapeutic particle engineering, the drying of crystalline active pharmaceutical ingredients (APIs), and encapsulation [1].

SDDs are used to increase bioavailability of poorly soluble APIs. Through proper formulation and selection of excipients, the SDD technology is applicable to compounds with a broad range of physiochemical properties [2]. SDD formulations generally include polymers that are used to increase stability of the amorphous form in the solid state, to increase the effective solubility of the drug relative to that of the crystalline drug form, and to inhibit crystallization of drug in solution in vivo upon dosing and dissolution [3, 4]. Polymers commonly used in SDDs are povidone, hydroxypropyl methylcellulose, and hydroxypropyl methylcellulose acetate succinate [2, 4]. This article presents a novel methodology for spray-drying process development that is applicable to SDD formulations using any of these polymers.

In common practice, spray-drying process development is often empirical and is experimentally driven. Traditional methods often use an iterative design of experiments (DOE) [5] or statistical treatment of the process parameters and resulting product attributes [6]. This is often a timeintensive exercise, requiring large quantities of API, and the resulting process is often not well understood or sufficiently robust. Recent efforts have focused on applying a spectrum of fundamental models to spray-drying process understanding, ranging from steady-state and equilibriumbased approaches to rate-based and computational fluid dynamics (CFD) models [7].

A primary objective of the "cGMPs for the 21st Century" initiative advocated by the Food and Drug Administration is to move away from a descriptive approach to one based on first principles. This paper presents a process-development approach that rationally combines these fundamental engi- 


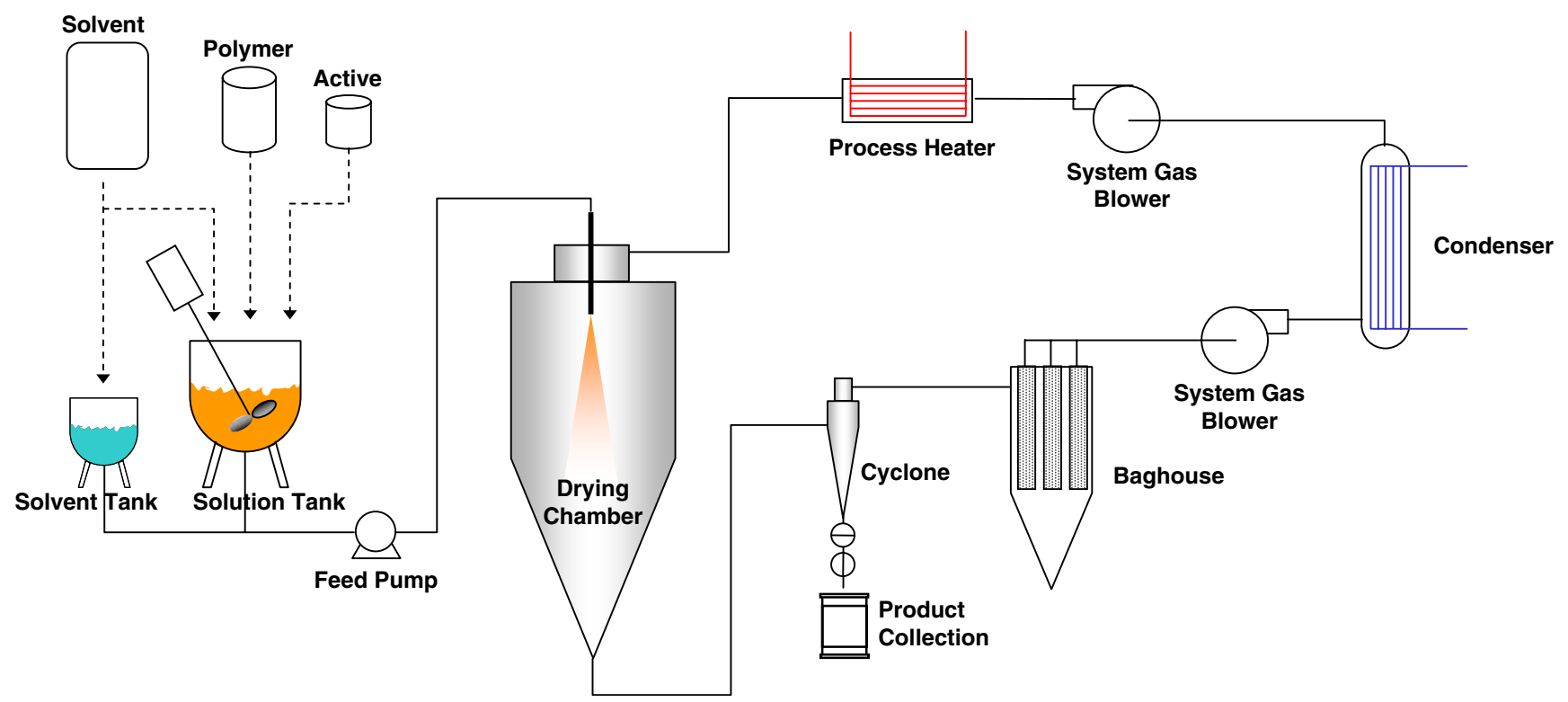

Fig. 1 General spray-drying equipment configuration

neering models with process-characterization tools to shorten process-development timelines and reduce the amount of API required. It represents a quality by design (QbD) approach that lays the groundwork for continuous improvement and eventual design-space process regulatory filings. This approach is in alignment with the current guidance on Pharmaceutical Development Q8(R1) [8].

This paper is the first of a two-part series. It describes the basic spray-drying process-development methodology, which employs a series of screening-scale spray-drying runs, offline experiments, and fundamental models, leading to quick and efficient initial process definition. The second paper in the series will address the methodology for optimization, scale-up, and definition of a design space for a commercial-scale spray-drying process.

\section{Spray-Drying Process Overview and Physical Situation}

The spray-drying process, shown in Fig. 1, is a wellestablished unit operation in the pharmaceutical industry [1]. To manufacture an SDD, a spray solution - which consists of API and polymer dissolved in a common solvent - is delivered to an atomizer inside a spray-drying chamber cocurrently with a hot drying gas. Organic solvents are typically used to produce SDDs because the API tends to be poorly water-soluble. Nitrogen drying gas is employed to provide an inert processing atmosphere when processing organic solvents. The spray solution is atomized into droplets using a spray nozzle. Many different types of spray nozzles can be used including two-fluid, ultrasonic, rotary, and pressure (or hydraulic) nozzles [9]. Pressure nozzles are often preferred due to their simplicity, scalability, and ease of droplet-size tuning [10]. When the spray-solution droplets contact the hot drying gas, the solvent in the droplets evaporates, leaving dried SDD particles entrained in the drying gas that exits the drying chamber. These particles are collected and then separated from the gas stream, usually by a cyclone separator.

Most laboratory-scale spray dryers operate in a singlepass mode where the drying gas is passed through the chamber only one time before it is vented to the appropriate waste stream. Many large pilot-scale and production-scale spray dryers operate in closed-loop or recycle mode where the solvent-laden drying gas is passed through a condenser, reheated, and introduced back into the drying chamber. The optimum process conditions for spray dryers operated in a recycle mode differ from those operated in a single-pass mode due to the influence of the solvent vapor in the inlet drying gas.

Two key control volumes, shown in Fig. 2, can be used to define the physical situation for spray-drying. The macroscopic control volume, comprising the entire drying chamber, defines the overall thermodynamic space based upon easily measured and monitored spray-drying process parameters. Mass-balance and energy-balance calculations can be conducted using the inputs and outputs from the drying chamber [7,9]. As described below, these calculations can be used to predict a continuum of outlet conditions across a range of inlet parameter values to characterize the spray-drying operating space and to define a process design space. 


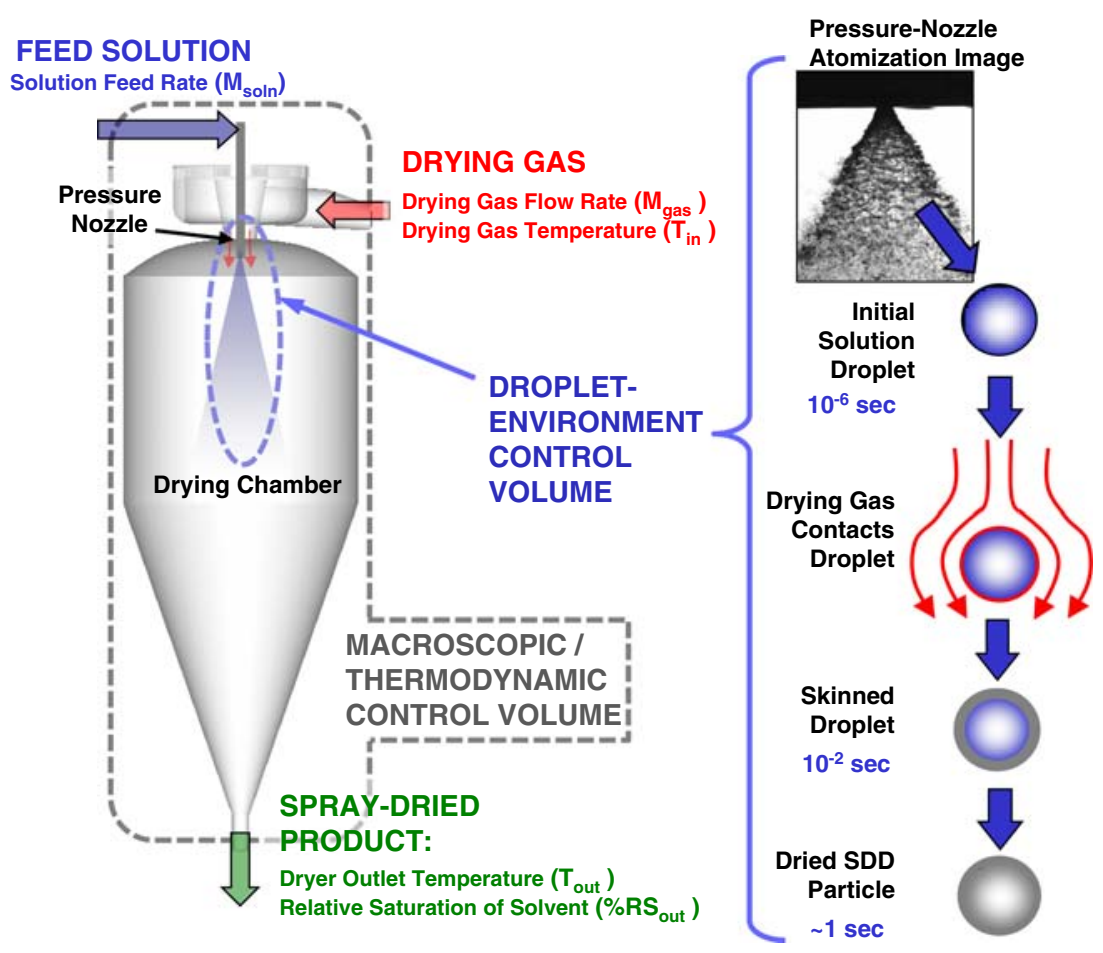

Fig. 2 Physical situation and key control volumes of the spray-drying process

Within the macroscopic control volume, the dropletenvironment control volume comprises individual droplet formation, droplet interaction with the drying gas that immediately surrounds the droplet, and solvent evaporation to form dry particles. Droplet-drying kinetics is defined in the droplet-environment control volume. Several key events occur within this control volume. First, on the scale of microseconds, droplets are formed via the atomization process. Second, on the scale of milliseconds, droplets in the atomization plume contact the hot drying gas and solvent evaporation begins. Solvent evaporation occurs quickly, increasing the concentration of solids at the surface of the droplet and forming a polymer "skin." The polymer skin resists solvent evaporation because the solvent must diffuse through the viscous skin. This entire droplet-drying process happens quickly; typically, dried particles are formed within approximately $1 \mathrm{~s}$. Within the context of process definition, this paper will address experimental and modeling approaches to gain insight into each of the events occurring within the droplet-environment control volume, both on an individual droplet level and across a distribution, as appropriate.

Understanding the key control volumes is critical to quantifying the multivariate relationship between product attributes and process parameters. Use of models and process-characterization tools aid in the quantitative understanding of the key control volumes, leading to rational definition of process parameters.

\section{Process-Development Flowchart Methodology}

The methodology in this paper clearly demonstrates that spraydrying process development based on this flowchart methodology requires no more time or API than standard formulation development. This methodology was conceived while screening hundreds of APIs as SDDs and progressing more than 25 SDD formulations to the clinic from early stage through late phase 3 scale-up to commercial scale (metric tons of SDD).

The process-development flowchart methodology (1) minimizes API usage during process development, (2) reduces process-development time, and (3) ensures process robustness during technology transfer to clinical manufacturing. This flowchart methodology and associated tools have been used to achieve a formulation and clinical-supply process using similar resources to those required for standard crystalline formulations.

The spray-drying process-development flowchart is shown in Fig. 3. Each box in the flowchart represents a process-development tool that is used to define the spraydrying process. These steps, which begin with the definition of a robust formulation, are executed in a sequence so that each step builds from the last, increasing the level of specificity at each step. The outputs are combined in an order that initially maximizes the acceptable operating space and increases process understanding for efficient process development and future scale-up. Each of the steps in the flowchart is described in the sections below. 


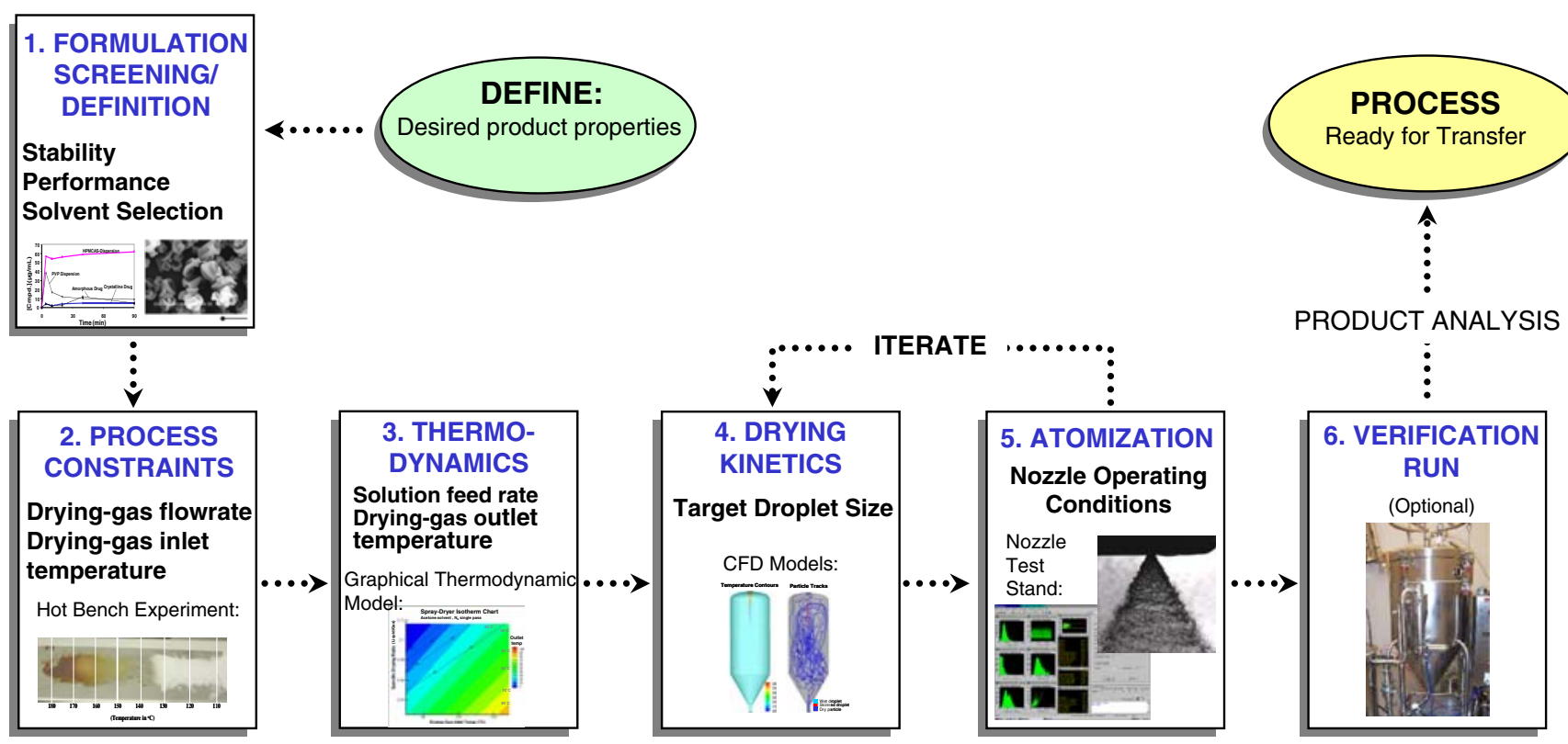

Fig. 3 Spray-drying process-development flowchart

\section{Formulation Screening and Definition}

In this step, a robust formulation is identified.

Based upon an evaluation of the physicochemical properties of the API, several initial formulations (generally, two to four) are selected and screened in this step [2]. A screening-scale spray dryer designed for maximizing yields from SDD batches of $<100 \mathrm{mg}$ is used. This dryer is not designed to replicate optimized bulk powder properties (e.g., particle size, density) of larger-scale spray dryers, but rather is used to match physicochemical properties for fast, efficient formulation-screening studies. Analogous to the process-development flowchart methodology, a formulation selection flowchart, comprising predictive physical-stability models, rapid chemical-stability screens, and biorelevant in vitro performance tests is key to selecting a lead SDD polymer and drug-to-polymer ratio. For the sake of brevity, these will not be addressed in this paper.

In a $\mathrm{QbD}$ approach, formulation and process are linked through identification of critical-to-quality attributes (CQAs) and key quality attributes (KQAs) which are related to critical process parameters and key process parameters (KPPs). Critical and key quality attributes and process parameters are defined in a criticality and risk assessment [11]. Using this methodology, process development is focused on the selection of spray-drying process parameters that result in the desired KQAs (e.g., particle size and density) and process performance (e.g., yield) with minimal impact on CQAs of bioperformance and stability.
Additional formulation information is gathered during this step, including preferred spray solvents and spray-solution solids contents. At the end of this step, a robust formulation has been selected based upon fundamental physicochemical properties. Typically, the entire formulation-screening step can be completed with about 200 to $400 \mathrm{mg}$ of API and, in some cases, as little as $100 \mathrm{mg}$ of API.

\section{Process Constraints}

After a robust formulation has been identified, equipmentrelated and formulation-related process constraints are identified, resulting in definition of the drying-gas flow rate $\left(M_{\text {gas }}\right)$ and drying-gas inlet temperature $\left(T_{\text {in }}\right)$.

As part of this methodology, constraints can be placed on the process based upon equipment limitations (e.g., maximum $M_{\text {gas }}$ or $T_{\text {in }}$ values) or formulation properties (e.g., glass-transition temperature $\left[T_{\mathrm{g}}\right]$ or thermal stability). These constraints can be defined experimentally using small quantities of SDD produced during the formulationscreening step.

For example, a hot-bench experiment can be used to define the maximum $T_{\text {in }}$ value. This involves spreading a small amount of the SDD across a metal strip with a known thermal gradient along its length. The powder can be observed for a time period relevant to a spray-drying run (e.g., a few hours) for signs of stickiness, melting, and visual discoloration or "browning." Conservatively, the maximum $T_{\text {in }}$ value can be limited to temperatures below the observed "sticking" or discoloration temperatures of the SDD. Identifying this constraint minimizes product deposits 
on hot spots inside the spray-drying chamber. Alternatively, spray-drying equipment can be designed to cool hot spots in the spray-drying chamber, relaxing this constraint [7]. The hot-bench experiment can be performed during formulation screening and uses approximately 100 to $200 \mathrm{mg}$ of SDD (i.e., 25 to $50 \mathrm{mg}$ of API).

\section{Thermodynamic Design Space}

In this step, a thermodynamic operating space is defined to form an initial design space. This design space is used to select a drying-gas outlet temperature $\left(T_{\text {out }}\right)$ and solution feed rate $\left(M_{\text {soln }}\right)$.

All of the key thermodynamic spray-drying process parameters and outlet conditions that affect product attributes can be related through fundamental relationships by applying a mass and energy balance using the spraydryer chamber as a control volume [9]. One or more of these parameters are often identified as a KPP during a QbD criticality assessment.

For a spray dryer operating in single-pass mode, the KPPs and outlet conditions are:

(1) $M_{\text {soln }}$;

(2) drying-gas flow rate $\left(M_{\text {gas }}\right)$;

(3) $T_{\text {in }}$;

(4) $T_{\text {out }}$; and

(5) relative saturation (or humidity) of the solvent at spray-dryer outlet conditions $\left(\% \mathrm{RS}_{\text {out }}\right)$.

Simplified equations for conservation of mass and energy relating all five key thermodynamic process parameters are shown below. ${ }^{1}$

The energy required to vaporize the solvent (i.e., energy out) is shown as:

$\Delta E=M_{\text {soln }} \times\left(1-x_{\text {solids }}\right) \times \Delta H_{\text {vap }}$

where $\Delta H_{\mathrm{vap}}$ is the heat of vaporization and $x_{\text {solids }}$ is the mass fraction solids in solution.

The energy lost by the drying gas (i.e., energy in) is shown as:

$\Delta E=M_{\text {gas }} \times c_{\mathrm{p}} \times\left(T_{\text {in }}-T_{\text {out }}\right)$

where $c_{\mathrm{p}}$ is the heat capacity of the drying gas:

$$
\begin{gathered}
M_{\text {soln }} \times\left(1-x_{\text {solids }}\right) \times \Delta H_{\text {vap }} \\
=M_{\text {gas }} \times c_{\mathrm{p}} \times\left(T_{\text {in }}-T_{\text {out }}\right) .
\end{gathered}
$$

\footnotetext{
${ }^{1}$ For spray dryers operating in recycle mode, the relative saturation at the inlet of the dryer must also be considered. Additional factorssuch as heat loss to the ambient surroundings-would need to be added if a poorly insulated spray-dryer system is used.
}

Solving for $T_{\text {out: }}$ :

$T_{\text {out }}=T_{\text {in }}-\frac{M_{\text {soln }} \times\left(1-x_{\text {solids }}\right) \times \Delta H_{\text {vap }}}{M_{\text {gas }} \times c_{\mathrm{p}}}$

and:

$T_{\text {out }}=\mathrm{f}\left(\mathrm{M}_{\text {soln }}, \mathrm{M}_{\text {gas }}, \mathrm{T}_{\text {in }}\right)$.

Solving for $\% \mathrm{RS}_{\text {out }}$ at the outlet conditions:

$$
\begin{aligned}
\% \mathrm{RS}_{\text {out }}= & 100 \times\left(\frac{P_{\text {chamber }}}{P^{*} T_{\text {out }}}\right) \\
& \times \frac{M_{\text {soln }}\left(1-x_{\text {solids }}\right) / \mathrm{MW}_{\text {solvent }}}{\left[M_{\text {soln }}\left(1-x_{\text {solids }}\right) / \mathrm{MW}_{\text {solvent }}+M_{\text {gas }} / \mathrm{MW}_{\text {gas }}\right]}
\end{aligned}
$$

where $\mathrm{MW}_{\text {solvent }}$ and $\mathrm{MW}_{\text {gas }}$ are the molecular weights for the respective species, $P_{\text {chamber }}$ is the absolute pressure in the spray-dryer chamber, and $P^{*} T_{\text {out }}$ is the equilibrium vapor pressure of the spray solvent evaluated at $T_{\text {out }}$.

The equations can be arranged to solve for spray-dryer outlet conditions as a function of $x_{\text {solids }}$ and $M_{\text {soln }}, M_{\text {gas }}$, and $T_{\text {in. }}$

In conventional methodologies, statistical DOE analysis is often used to understand the relationship of key process variables $[5,6]$. While such a statistical approach provides insight into the relationships between process parameters and product attributes, it is not based in the fundamental physics of the process and has limited ability to translate across scales and formulations. The purely statistical approach also requires large numbers of experiments (and, thus, large quantities of API) to fully characterize a narrow space.

Rather than purely empirical or statistical methods, the spray-drying process-development flowchart methodology relies on the mass and energy balance to calculate outlet conditions based upon input parameters without the use of experiments. This fundamental approach allows all five key spray-drying process parameters to be plotted on the same multivariate graph. The plot can be generated theoretically (i.e., without experiments) and the resulting multivariate graph can be a powerful experimental guide that can be used to convey an operating or design space.

An example thermodynamic operating space is shown in Fig. 4. The specific drying ratio shown in Fig. 4 is defined as the mass ratio of solution feed rate to drying-gas flow rate. Defining the specific drying ratio allows the operating space for multiple scales of spray dryers to be represented on the same plot. When considering a single-scale spray dryer, the drying gas flow rate is typically maximized and held constant which simplifies the specific drying ratio a single variable: $M_{\text {soln }}$. The specific drying ratio is plotted against $T_{\text {in }}$, resulting in contours of constant dryer outlet conditions such as temperature and relative solvent saturation. 
Fig. 4 Definition of a thermodynamic operation space and processing design space, showing colored contours by $T_{\text {out }}$ and dashed isometric lines by $\% \mathrm{RS}_{\text {out }}$

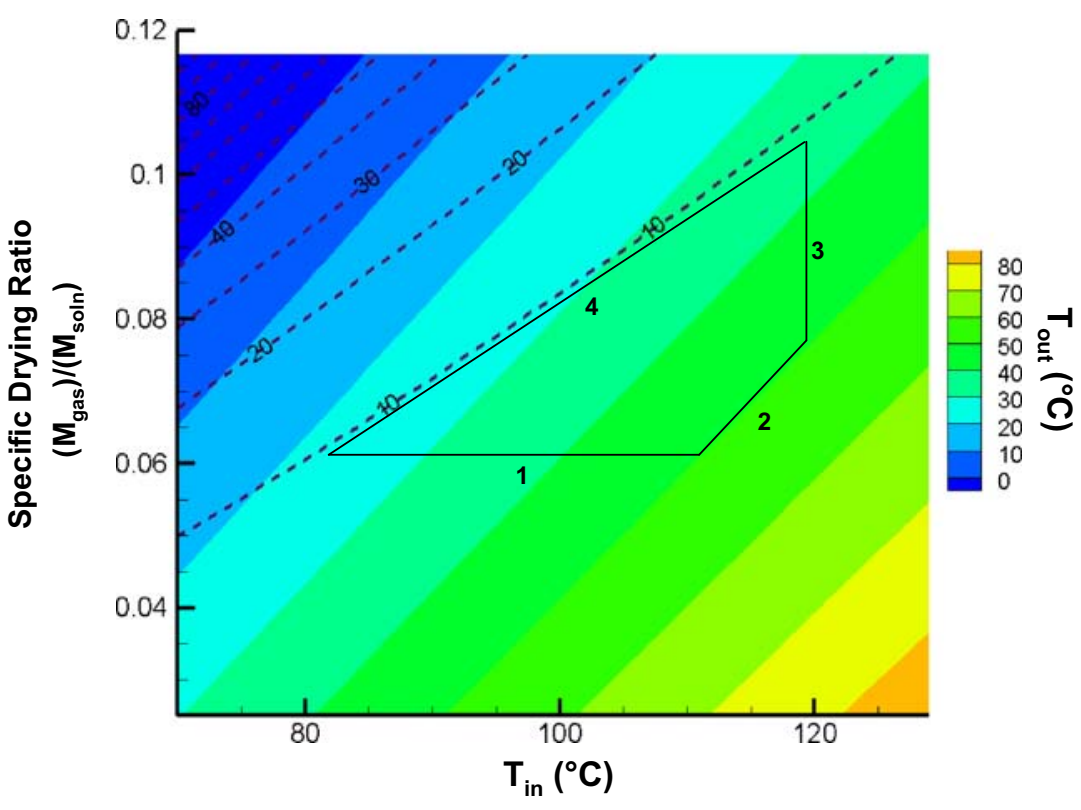

A design space within this operating space may be defined by applying process constraints based upon equipment limitations and formulation attributes defined in step 2. Figure 4 shows an example design space that is optimized for throughput, product density, residual solvent content, and yield based on the following constraints:

(1) Minimum specific drying ratio $\left(M_{\mathrm{soln}} / M_{\mathrm{gas}}\right)$, driven by target process throughput, is defined based on processefficiency requirements. In this example, a minimum specific drying ratio of 0.06 was defined to ensure that throughput was sufficient to meet the requirements for processing time.

(2) Maximum $T_{\text {out }}$ is determined based on thermal degradation/inactivation of the formulation or product-property constraints such as SDD specific density. For this example, the maximum $T_{\text {out }}$ was defined as $50^{\circ} \mathrm{C}$ based on previous observations that SDD specific density did not meet product specifications above this temperature.

(3) Maximum $T_{\text {in }}$ is defined in step 2. For this example, the maximum $T_{\text {in }}$ was defined as $120^{\circ} \mathrm{C}$ to ensure that the SDD formulation would not stick at the drying-gas inlet into the spray dryer.

(4) Minimum $T_{\text {out }}$ is determined based upon the relationship of the formulation $T_{\mathrm{g}}$ to the relative saturation at the dryer outlet. ${ }^{2}$ Below this $\% \mathrm{RS}_{\text {out }}$ value, insufficient drying leads to low collection yields and product

\footnotetext{
$\overline{2}$ This near-equilibrium assumption is usually acceptable at early stages of process development in single-pass spray dryers. For laterstage development involving closed-loop spray dryers (where $\% \mathrm{RS}_{\text {out }}$ is higher due to solvent in the inlet drying gas), further kinetic analysis is required to define this limit.
}

buildup inside the drying chamber caused when "wet" or "sticky" particles contact the dryer walls. For this example, an upper limit of $10 \% \mathrm{RS}_{\text {out }}$ was defined due to the $T_{\mathrm{g}}$ of the SDD formulation used in this example.

The above constraints may be narrowed or additional constraints may be applied based on specific product attributes (e.g., particle morphology) that may be desired (this is discussed in more detail in step 4). For example, lines of constant product attributes such as SDD bulk density may be drawn on the thermodynamic operating space and used to narrow the design space to the target SDD bulk density.

\section{Drying Kinetics}

Up to this point, a robust formulation and four process parameters ( $T_{\text {in }}, M_{\text {soln }}, T_{\text {out }}$, and $M_{\text {gas }}$ ) have been defined. In this step, target droplet size is defined based on dryingkinetic limitations.

The thermodynamic operating space described above defines the process based upon near-equilibrium assumptions and does not account for kinetic limitations such as the drying of large droplets or increased drying resistance due to film formation at the droplet surface. Drying kinetics of single droplets can be studied experimentally [12, 13], but the information provided-while useful - does not account for the actual conditions in the spray dryer such as droplet velocity and momentum exchange between the droplets and the drying gas.

CFD modeling can be used to study drying kinetics at conditions that are representative of conditions inside the spray dryer $[14,15]$. When modeling the drying of filmforming solutions, additional algorithms may need to be 
added to the model to account for the increased drying resistance due to the formation of a skin or film at the surface of the droplet. These formulation-specific algorithms are based on different droplet-drying equations for each of the drying regimes (e.g., initial solvent evaporation, skin formation, diffusion of the solvent through the skin) and can be validated with offline experiments (using placebo formulations or small quantities of API). In addition to other methods, these experiments are performed using a thermal gravimetric analyzer ${ }^{3}$ in which a temperature-controlled thin film of solution is evaporated and its weight monitored over time. The drying data that are generated are used to estimate (1) the solids concentration at which a "skin" will form at the surface during drying and (2) the solvent diffusivity through the "skin" at a given temperature.

Placebo formulations using the polymer can be successfully used to represent the bulk drying behavior due to (1) the relative amount of polymer in the SDD formulation (typically, $\geq 50 \%$ by weight to active); (2) the high molecular weight of the polymer, which dominates the rheological properties of the solution (e.g., viscosity and surface tension); and (3) the film-forming nature of the polymer, which is largely responsible for drying phenomena.

Model simulations are conducted across a range of droplet sizes at the target thermodynamically defined process parameters. The output of these simulations defines the maximum target droplet size. Typically, droplet size is maximized for SDD formulations to produce large particles (e.g., 50 to $100 \mu \mathrm{m}$ ) with acceptable flow properties for further processing into dosage forms. Thus, the target droplet size is generally selected to be the largest that will result in dry particles exiting the drying chamber without "wet" or "sticky" particles contacting the dryer walls. Model outputs shown in Fig. 5 include the temperature profile in the drying chamber and droplet-drying histories.

If the CFD models and algorithms are validated against relevant experimental systems, they can be used to simulate spray-drying runs. Validated CFD models allow multiple operating conditions to be studied without conducting trial spray-drying runs with API. ${ }^{4}$ CFD modeling approaches allow rapid optimization of drying kinetics and are particularly useful during scale-up to production or commercial scale where trial runs can be particularly timeintensive and API-intensive.

Drying kinetics also define particle morphology and density for many formulations. SDD morphology is a strong function of drying kinetics due to the film-forming

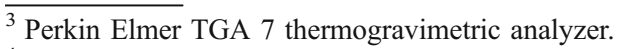

${ }^{4}$ The need for model validation cannot be understated. Each model input (e.g., droplet-size distribution and velocity, drying-gas flow, velocity pattern, and thermodynamic parameters) and model outputs should be validated using offline experiments and placebo trial runs.
}

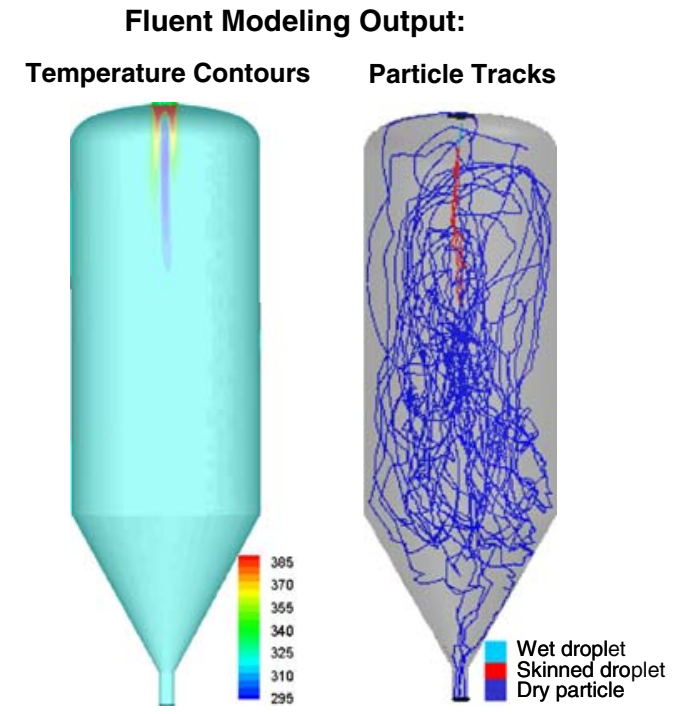

Fig. 5 Example CFD simulation output for a specified set of process parameters, showing temperature contours on the left and particle tracks on the right, indicating the particle characteristics (wet droplet, skinned or sticky droplet, or dried particle)

properties of commonly used polymers. Particle morphology can be related to process parameters using dimensionless correlations such as the Peclet number [16]. These correlations can define when a skin is likely to form at the particle surface during droplet drying. This phenomenon can also be studied experimentally using an individual droplet apparatus $[12,13]$.

Figure 6 shows the effect of drying conditions (i.e., hot/ fast and cold/slow) on particle morphologies. This example, for demonstration purposes, varies based on solution properties for a given formulation. In the case of hot/fast drying, the droplet temperature is near or above the boiling point of the solvent when droplet skin forms. This causes the vapor pressure in the particle to keep it "inflated" when it dries, producing a hollow-sphere morphology. In the case of cold/slow drying, the droplet temperature is below the boiling point of the solvent when the droplet skin forms, causing the particle to collapse into a "raisin" morphology. These kinetic morphology considerations can be combined with the thermodynamic operating space defined in step 3 and mapped within the design space.

Drying-kinetic considerations are particularly important during spray dryer scale-up where additional factors must be considered [17]. Key scale-up considerations include the presence of solvent vapor in the inlet drying gas and less mixing of the droplets and drying gas [18]. In practice, it is common to see a distribution of particle morphologies. However, drying parameters may be tuned so that the majority of the dried particles are of a specific desired morphology. 
Fig. 6 High-speed images of pressure-nozzle atomization and droplets suspended on thermocouples subjected to various drying conditions, showing images for individual dropletdrying experiments for $a$ hot/fast drying conditions and $b$ cold/ slow drying conditions when a film-forming polymer is used in acetone solution a) HOT / FAST DRYING

Gas Temperature $\left(T_{\text {in }}\right)=65^{\circ} \mathrm{C}$

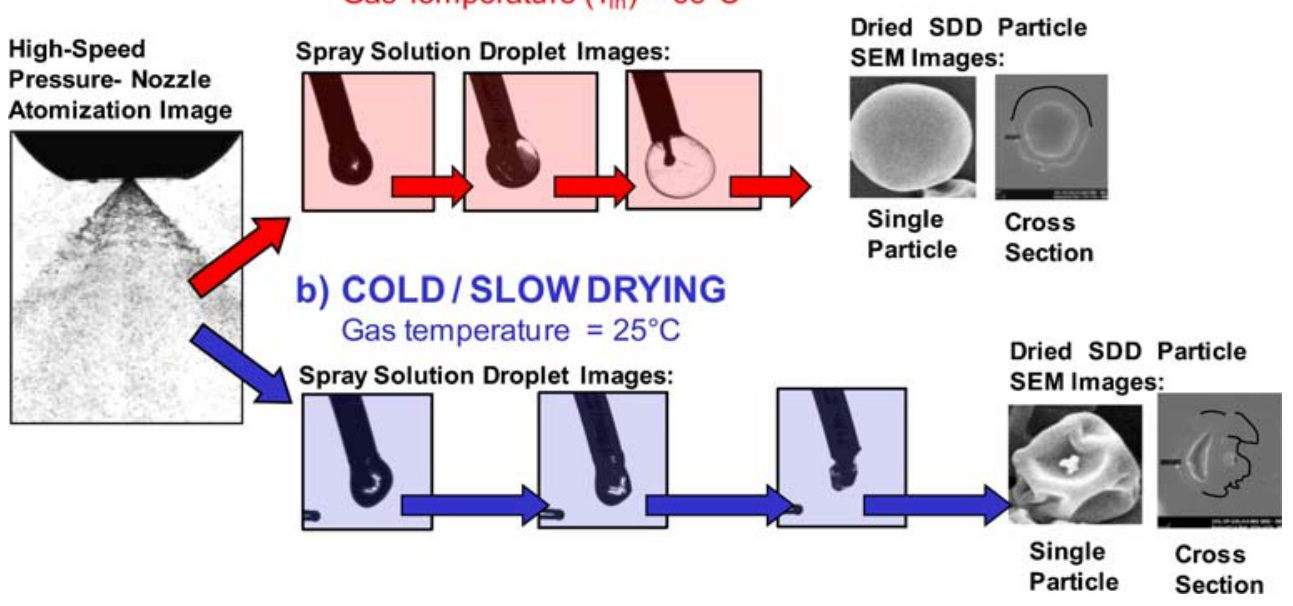

\section{Atomization Parameter Selection}

In this step, the spray-drying nozzle is selected and atomization parameters are defined to produce the target droplet size defined in step 4.

The target droplet size from the atomizer is defined based on the maximum droplet size defined in step 4 and the desired particle-size distribution for the product. Droplet size and solution solids content directly correlate to the final size of the dried particle based on the following correlation:

$D_{\text {particle }} \cong D_{\text {droplet }} \times \sqrt[3]{x_{\text {solids }} \times \frac{\rho_{\text {droplet }}}{\rho_{\text {particle }}}}$,

where $D_{\text {particle }}$ is the diameter of the dried particle, $D_{\text {droplet }}$ is the diameter of the droplet, $\rho_{\text {particle }}$ is the density of the dried particle, and $\rho_{\text {droplet }}$ is the density of the spray solution.

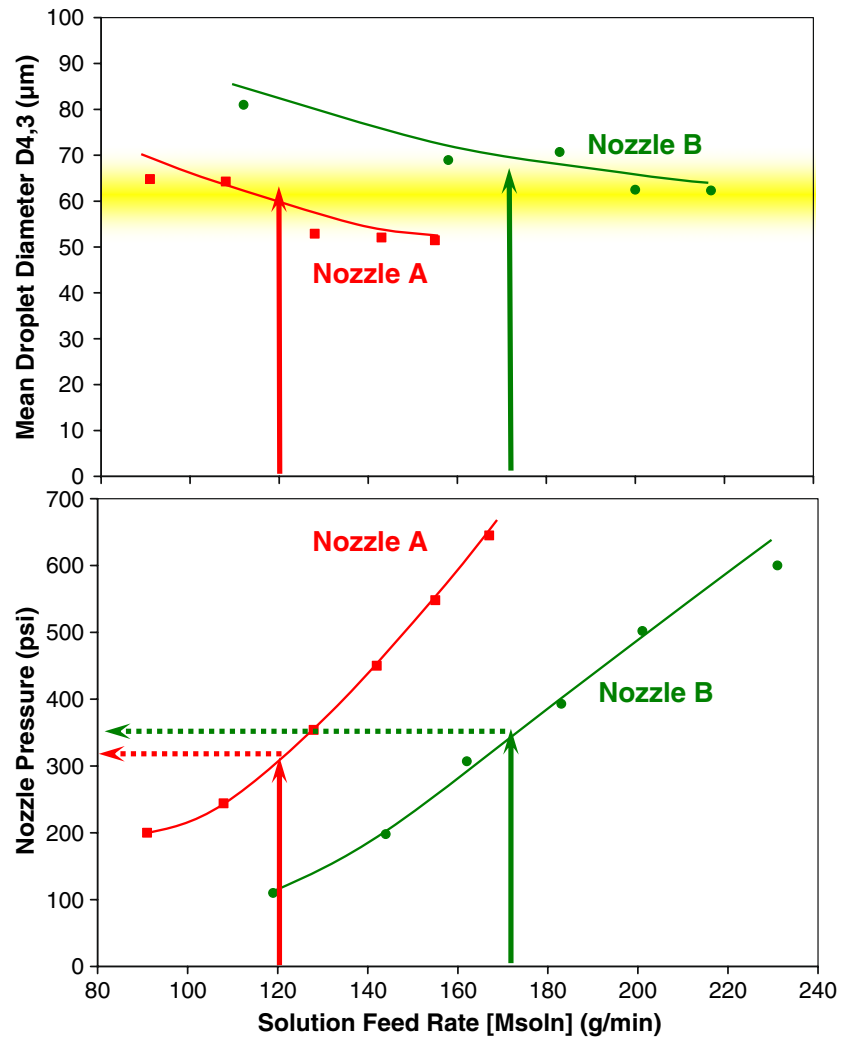

Fig. 7 Example PDPA output from a nozzle test stand for two pressure nozzles of different dimensions
Table 1 Spray-drying process-development case study using flowchart methodology

\begin{tabular}{|c|c|c|c|}
\hline Flowchart step & Process parameter defined & $\begin{array}{l}\operatorname{Time}^{\mathrm{a}} \\
\text { (h) }\end{array}$ & $\begin{array}{l}\mathrm{API}^{\mathrm{a}} \\
(\mathrm{mg})\end{array}$ \\
\hline $\begin{array}{l}\text { 1. Formulation screening/ } \\
\text { definition }\end{array}$ & $\begin{array}{l}\text { API/polymer ratio } \\
\text { Spray solvent } \\
x_{\text {solids }}\end{array}$ & 2 & 145 \\
\hline 2. Process constraints & $\begin{array}{l}T_{\text {in }} \\
M_{\text {gas }}\end{array}$ & 1 & $50^{\mathrm{b}}$ \\
\hline $\begin{array}{l}\text { 3. Thermodynamic design } \\
\text { space }\end{array}$ & $\begin{array}{l}M_{\text {soln }} \\
\text { Upper and lower limit of } \\
T_{\text {out }} \text { and } \% \mathrm{RS}_{\text {out }}\end{array}$ & 1 & 0 \\
\hline 4. Drying kinetics & $\begin{array}{l}T_{\text {out }} \\
\mathrm{RS}_{\text {out }}\end{array}$ & $1^{\mathrm{c}}$ & 0 \\
\hline $\begin{array}{l}\text { 5. Atomization parameter } \\
\text { selection }\end{array}$ & $\begin{array}{l}\text { Nozzle size } \\
\text { Atomization pressure } \\
\text { Atomizer droplet size }\end{array}$ & 3 & 0 \\
\hline $\begin{array}{l}\text { 6. Verification spray- } \\
\text { drying experiments/SDD } \\
\text { supplies to support tech- } \\
\text { nology transfer }\end{array}$ & $\begin{array}{l}\text { Confirmation that spray- } \\
\text { drying process meets for- } \\
\text { mulation targets }\end{array}$ & $3^{\mathrm{d}}$ & $500^{\mathrm{c}}$ \\
\hline Totals & & 11 & 645 \\
\hline
\end{tabular}

${ }^{\text {a }}$ Required for process development

${ }^{\mathrm{b}}$ Used remaining SDD from step 1

${ }^{\mathrm{c}}$ Used CFD modeling results for similar formulation from database

${ }^{\mathrm{d}}$ One or two placebo runs and active run 
Droplet size is a function of (1) atomizer geometry; (2) spray-solution attributes (e.g., viscosity and surface tension); and (3) atomization parameters (e.g., nozzle pressure and $M_{\text {soln }}$ ) [19]. Pressure nozzles are preferred for SDD formulations due to their suitability for viscous filmforming solutions, robust operation, and scalability. Pressure nozzles have been well studied and characterized [10]. Correlations between droplet size, solution properties, and nozzle geometry are available in the literature and can be used to guide initial nozzle selection.

For a specific spray-solution formulation, droplet size can be measured experimentally using placebo or model solutions (matching surface tension and viscosity) to confirm nozzle selection and nozzle operating parameters. Figure 7 shows example experimental data from a phase Doppler particle analyzer (PDPA). In this example, two pressure nozzles were selected based on the desired $M_{\text {soln }}$ value, as defined by the thermodynamic design space in step 3 . The nozzles were characterized to define nozzle pressure drop and particle size versus $M_{\text {soln }}$. These data are then used to select the nozzle and operating pressure that gives the previously defined target droplet size and feed rate.

\section{Verification Spray-Drying Experiments (Optional)}

At this point, a robust formulation and set of process parameters has been defined. In this optional step, a spraydrying trial run is completed to verify the conditions defined using the process-development flowchart.

Up to this point in the process-development flowchart, only screening-scale spray-drying runs, offline experiments, and models have been used, requiring minimal API. This is illustrated in Table 1, which shows the time and API for each step of the flowchart for an example case study using this methodology. ${ }^{5}$

In this example, the spray-drying process-development flowchart methodology was successfully used to rapidly and efficiently define a robust formulation and spray-drying process suitable for manufacture of materials for clinical trials at the pilot scale (approximately $4 \mathrm{~kg}$ of SDD per batch manufactured).

The flowchart methodology provided the following outcomes:

(1) use of $<700 \mathrm{mg}$ of API for all process-development activities;

(2) rapid definition ( $<3$ weeks, $11 \mathrm{~h}$ of total experimental time) of a robust spray-drying process at pilot scale (using a Niro Mobile Minor ${ }^{\mathrm{TM}}$ spray dryer) using small-scale experiments and fundamental models;

\footnotetext{
${ }^{5}$ The time requirements shown are limited to those related to processdevelopment experiments and do not include time for tasks such as characterization of material bulk properties, performance, and stability.
}

(3) successful completion of an SDD clinical manufacturing campaign in $<3$ months from initial processdevelopment activities; and

(4) replication of key product attributes (e.g., bulk properties and bioperformance) between development and clinical scales.

\section{Conclusions}

The outcome of the spray-drying process-development flowchart methodology allows formulation and process definition using time and resources similar to those required for conventional immediate-release crystalline formulations. The methodology, which is based on fundamental engineering models and state-of-the-art process-characterization tools, can be used as an alternative to traditional empirical spray-drying process-development methods, resulting in streamlined and robust process development.

This model-based process development represents a QbD approach that lays the groundwork for continuous improvement and eventual design-space process regulatory filings. This approach is in alignment with the current guidance on Pharmaceutical Development Q8(R1). Many aspects of this approach can be directly translated to other atomization/evaporative processes, such tablet-coating and fluid-bed processes. A similar strategy can also be applied to many other pharmaceutical-processing unit operations.

Acknowledgments We would like to acknowledge the contributions of Pfizer, Tim Hagen, Ravi Shanker, and our colleagues at Bend Research for their support of this work. We would also like to thank the reviewers for their input into this manuscript.

Open Access This article is distributed under the terms of the Creative Commons Attribution Noncommercial License which permits any noncommercial use, distribution, and reproduction in any medium, provided the original author(s) and source are credited.

\section{References}

1. Vehring R. Pharmaceutical particle engineering via spray-drying. Pharm Res. 2007;25:999-1022.

2. Friesen DT, et al. Hydroxypropyl methylcellulose acetate succinate-based spray-dried dispersions: an overview. Mol Pharm. 2008;5:1003-19.

3. Curatolo W, Nightingale J, Herbig S. Utility of hydroxypropylmethylcellulose acetate succinate (HPMCAS) for initiation and maintenance of drug supersaturation in the GI milieu. Pharm Res. 2009;26:1419-31.

4. Gao P. Amorphous pharmaceutical solids: characterization, stabilization, and development of marketable formulations of poorly soluble drugs with improved oral absorption. Mol Pharm. 2008;5:903-4. 
5. Maltesen MJ, et al. Quality by design — spray-drying of insulin intended for inhalation. Eur $\mathrm{J}$ Pharm Biopharm. 2008;70:828-38.

6. Prinn K, et al. Statistical modeling of protein spray-drying at the lab scale. AAPS PharmSciTech. 2002;3(1):E4.

7. Oakley DE. Spray dryer modeling in theory and practice. Dry Technol. 2004;22:1371-402.

8. Anonymous. Guidance for industry: Q8(R1) pharmaceutical development. U.S. Department of Health and Human Services, Food and Drug Administration, Center for Drug Evaluation and Research (CDER), and Center for Biologics Evaluation and Research (CBER); 2009. http://www.fda.gov/downloads/Drugs/ GuidanceComplianceRegulatoryInformation/Guidances/ ucm073507.pdf/. Accessed 30 June 2009.

9. Masters K. Spray-drying handbook. Essex: Longman Scientific \& Technical; 1991.

10. Khavkin Y. Theory and practice of swirl atomizers. New York: Taylor \& Francis; 2004.

11. Garcia T, Cook G, Nosal R. PQLI key topics - criticality, design space, and control strategy. J Pharm Innov. 2008;3(2):60.
12. Sloth J, et al. Spray-drying of suspensions for pharma and bioproducts: drying kinetics and morphology. Ind Eng Chem Res. 2009;48:3657-64.

13. Sloth J, et al. Model based analysis of the drying of a single solution droplet in an ultrasonic levitator. Chem Eng Sci. 2006;61:2701-9.

14. Langrish TAG, Fletcher DF. Spray-drying of food ingredients and applications of CFD in spray-drying. Chem Eng Process. 2006;40:345-54.

15. Oakley DE. Scale-up of spray dryers with the aid of computational fluid dynamics. Dry Technol. 1994;12:217-33.

16. Vehring R, Foss WR, Lechuga-Ballesteros D. Particle formation in spray-drying. J Aerosol Sci. 2007;38:728-46.

17. Thybo $\mathrm{P}$, et al. Scaling up the spray-drying process from pilot to production scale using an atomized droplet size criterion. Pharm Res. 2008;25:1610-20.

18. Walton DE. The morphology of spray-dried particles. Ph.D. thesis, Aston University, Birmingham, UK, 1994.

19. Schwartzbach H. A risk-based approach to product and process quality in spray-drying. Pharm Technol. 2008. 